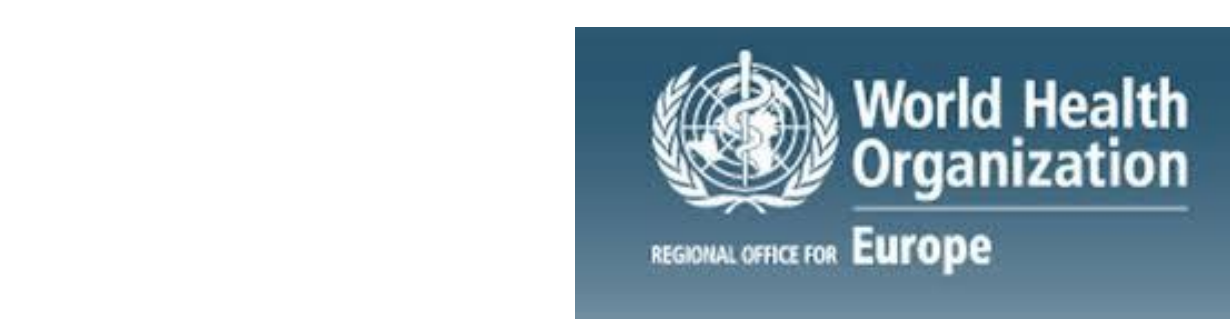

\title{
Social disadvantage and physical activity promotion: a European perspective
}

Niamh Murphy, WIT, Waterford, Ireland

Maureen Kidd, NHS Scotland

Matthias Braubach, WHO Regional Office for Europe, ECEH Bonn

Christian Schweizer, WHO Copenhagen

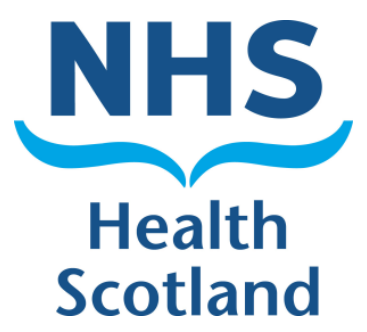




\section{Physical inactivity is a leading risk factor for health in Europe, associated with nearly 1 million deaths/year}

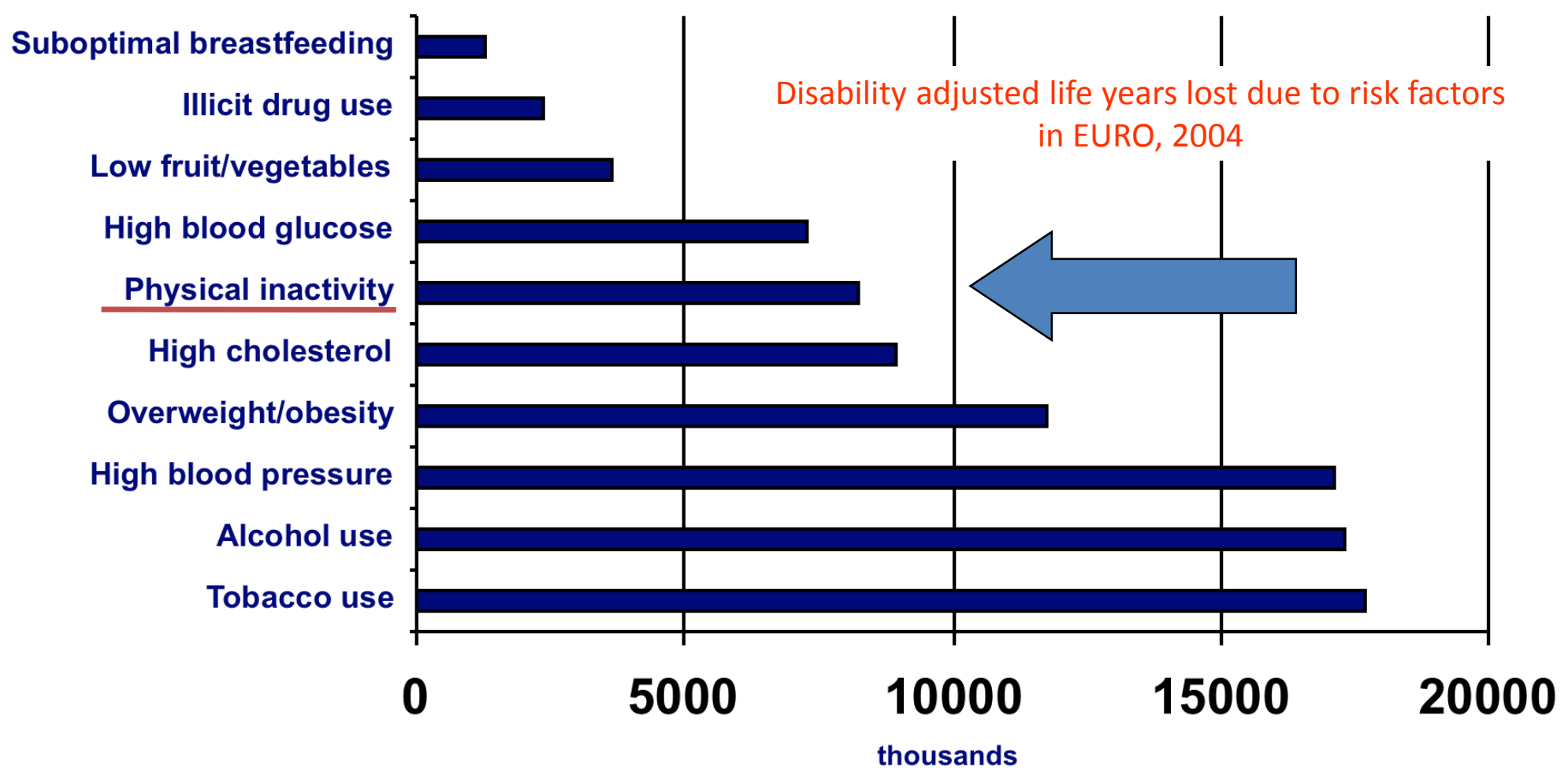

Source: Global Health Risks.. Geneva, World Health Organization, 2009

(http://www.who.int/healthinfo/global_burden_disease/global_health_risks/en/index.htmlL). 
- Co-funded by the European Union (Health programme) and supported by the Health Enhancing Physical Activity (HEPA) Europe network.

- One work package on guidance on physical activity promotion in socially disadvantaged groups, with a focus on healthy environments

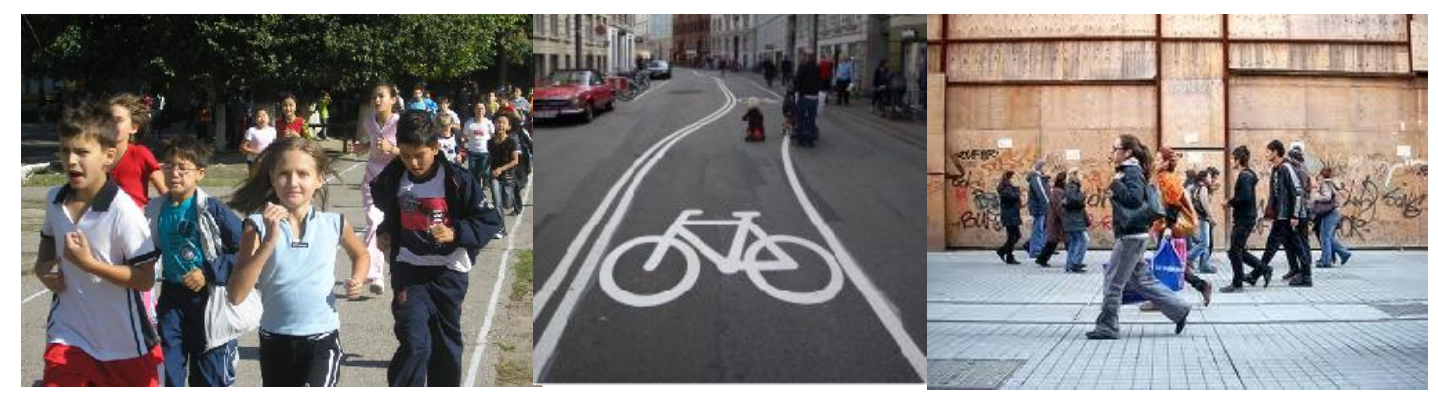


- Share what we know

- Reach consensus on EU guidance for PA promotion in socially disadvantaged groups

- Review of evidence, of practice, of policy

- A broad definition of "social disadvantage"

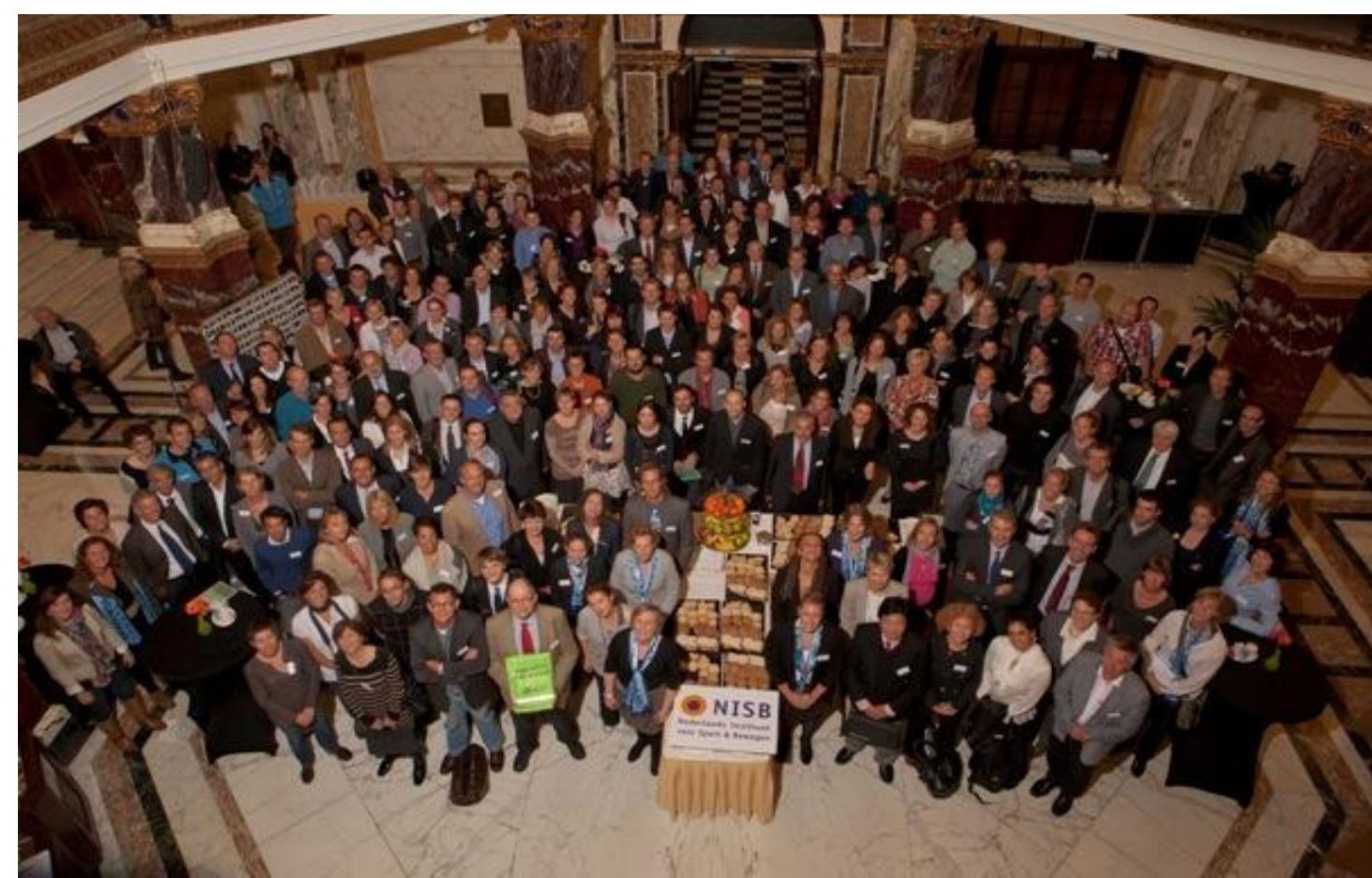


- Social disadvantage relates to socioeconomic aspects (including income, employment, education and socioeconomic status) as well as to sociocultural aspects (such as gender, ethnicity, religion, culture, migrant status, social capital), sociogeographical aspects (such as living in a deprived neighbourhood) and age.

- Socially disadvantaged groups may actually be disadvantaged by more than one of these dimensions 


\section{General working papers}

Physical activity promotion in socially disadvantaged groups

- A summary of European case studies -

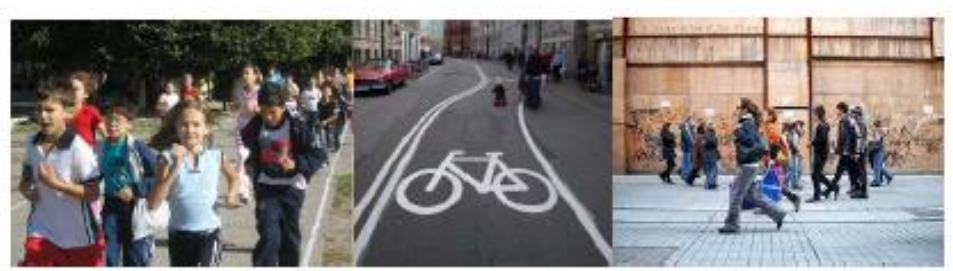

Working paper 1

Physical Activity Promotion in Socially Disadvantaged Groups - Evidence and Actions, 11-12 April 2011, Bonn, Germany

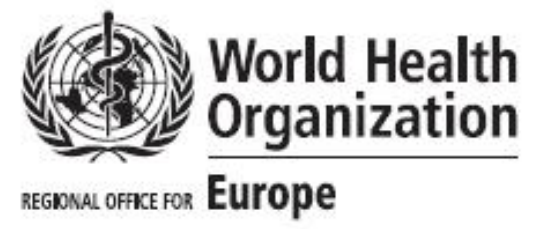

Impact of social disadvantage on physical activity levels in Europe

- A review of the evidence and recommendations for action -

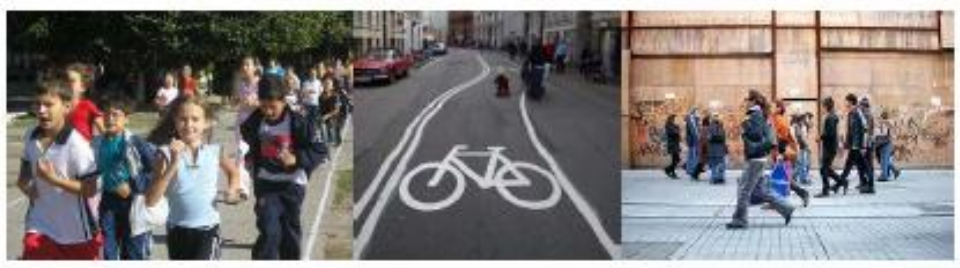

Working paper 2

Physical Activity Promotion in Socially Disadvantaged Groups

- Evidence and Actions, 11-12 April 2011, Bonn, Germany 
Evidence Review: All EU member states except Romania. Data for 41 of the 50 internationally recognized sovereign states with territory located in Europe. 89 European studies, and 6 review studies included

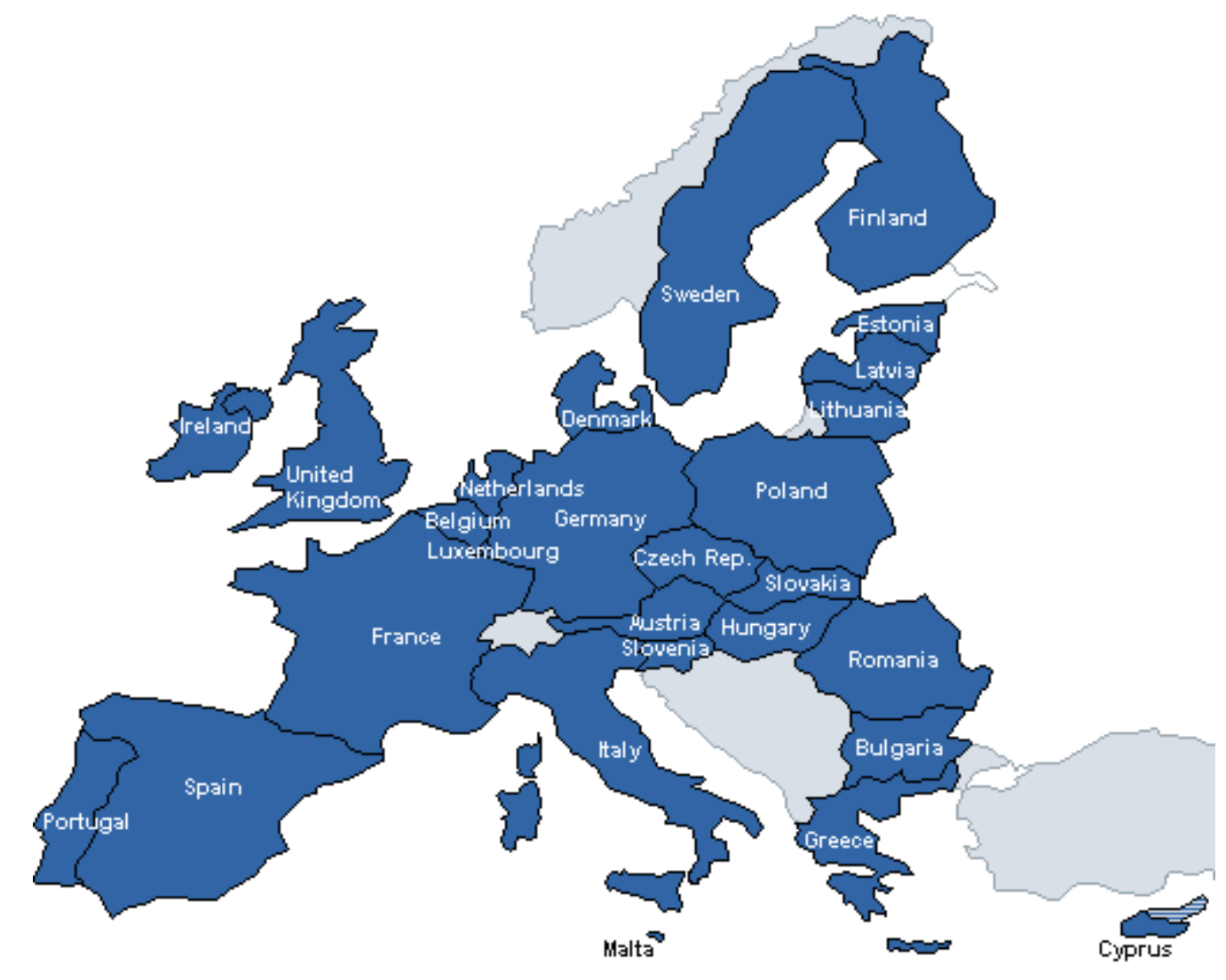




\section{Evidence Review}

- Physical activity analysed by social class (or education, employment, ethnicity etc). Health surveys which just reported gender differences in physical activity were excluded, except where SES measures were also reported.

- For countries where physical activity studies were not located, sports participation data were included.

- Where no large scale studies could be found for a given country, smaller studies were included, although some used non-representative samples, or less robust methods. Not a systematic review. The aim was to obtain a representative overview across as many countries as possible. 
Section 1: Is there social disadvantage in physical activity (PA), and sport participation in Europe?

YES!

- Adults: In the more developed, affluent nations, adults of low socioeconomic position (SEP) are less active during leisure time than those of high SEP. Gradient less clear for occupational PA, domestic PA and travel as these domains have been measured less frequently. Inconsistent associations for some countries in transition in Europe (Croatia, Czech Republic).

- Children and adolescents: Relationship between SEP and PA is not as consistent for children and adolescents as it is for adults.

- Ethnic minority groups: generally less active during leisure time than the general population. European literature is sparse, compared to the U.S. and Australia.

- Limited European research on the possible mechanisms behind social class differentials in PA. 


\section{Case Study Review}

- Called for case studies across European region via several routes (direct email; cascade via relevant networks; and web postings)

- 95 case studies (91 of these eligible)

- 13 Member States represented (but mainly north, west, and south of region)

- 70 came from UK, Germany, Finland and the Netherlands

- Each case study assessed four times

- Initial selection (22 projects) broadened to fill gaps and capture specific learning

Ended up with 29 case studies from 9 Member States 


\section{What we found: Results}

- Some studies reported achievement of outcomes (but this not always supported by evidence)

- Evaluations ranged from RCTs to practically no evaluation at all . Two projects used economic analysis - positive story. Funding for community based projects in Europe is often short-term and piecemeal and it is not surprising that PA projects are often not evaluated, and rarely published.

- Inspiring individual stories! but limited in terms of depth and representation across European Region

- Promoting PA is valued as means to improve social inclusion, provide diversionary activity and increase employability - and projects such as StreetGames are exemplars of good practice

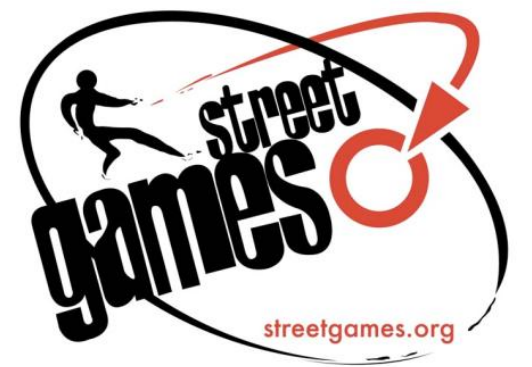


- The case study review highlighted the 'added value' of PA as a means to achieve wider social outcomes beyond health (social inclusion, employability) and the importance of multiagency partnership working. However, it highlighted the need for improved outcomesbased planning and evaluation. 


\section{Working papers}

A content analysis of physical activity policies in the $27 \mathrm{EU}$ member states with a focus on socially disadvantaged groups

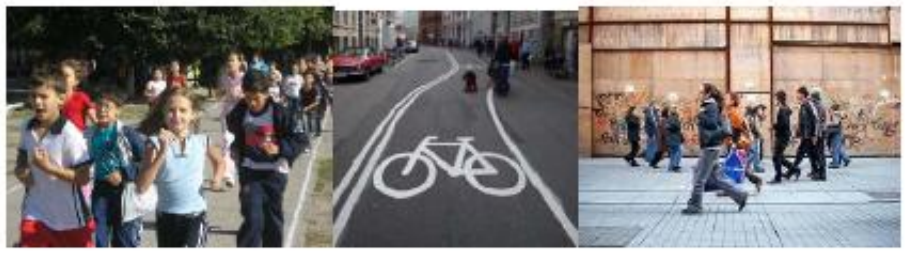

Working paper 1

Physical activity promotion in socially disadvantaged groups policy actions. 19-20 March 2012, Bonn, Germany

- NOT FOR PUBLIC USE / DISSEMINATION -
A Review and Evaluation of National Responses to a WHO Questionnaire on Physical Activity Policy

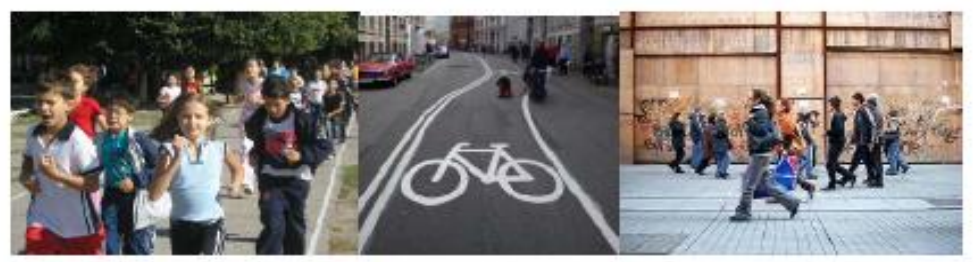

Working paper 2

Physical activity promotion in socially disadvantaged groups policy actions. 19-20 March 2012, Bonn, Germany

- NOT FOR PUBLIC USE / DISSEMINATION - 


\section{Policy analysis Results}

- 127 documents in WHO European database on nutrition, obesity and physical activity (NOPA) relating to physical activity in the 27 EU Member States (MS)

- 31 selected for further analysis

- $23 \mathrm{MS}$ represented in the analysis (not for Cyprus, Greece, Italy and Romania)

- Policy survey, MS responded. 
- Most respondents (95\%)have national policies or regulations promoting physical activity

- Just over half have policies focusing on physical activity in the disadvantaged

- Social disadvantage is described in a wide variety of ways and is seldom well-defined in policies

- Policy formulation tends to be vague (if at all)

- Conclusions on successful ways of working with disadvantaged groups overlaps with general PA approaches - the difference is HOW, not WHAT 


\section{Cad ata a dheanamh anois? What next?}

Co dál ?

Mis saab edasi?

was dann? Mitä seuraavaksi?

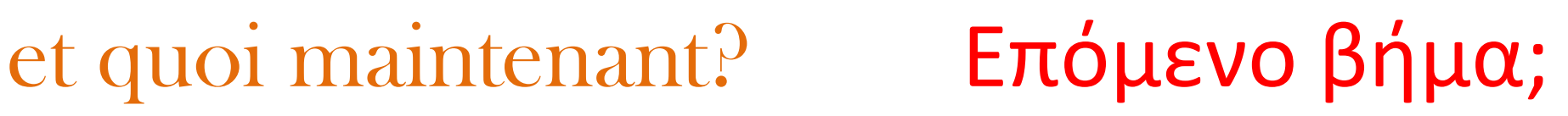


Final Report will be published in January 2013

Need to improve physical activity....

...measurement in population subgroups

....policy formulation wrt to disadvantaged populations

....evaluation of interventions targeting disadvantaged g|

....processes

Huge value in networking and collaboration

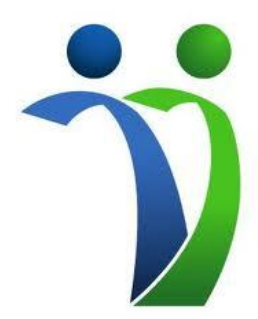

BUT

We don't always do it well.

E.g. 5 projects on social inclusion and sport funded under the EU Preparatory Action for Sport programme, between 2010 and 2012 but no systematic provision for sharing results, reaching consensus, influencing policymakers 
The value of networking and sharing.

Physical activity researchers will need to be proactive in helping overcome the considerable barriers to working with hardto-reach populations, including difficulties of recruitment, retention, programme tailoring and flexible delivery, as well as partnership working to make a difference in getting people more active.

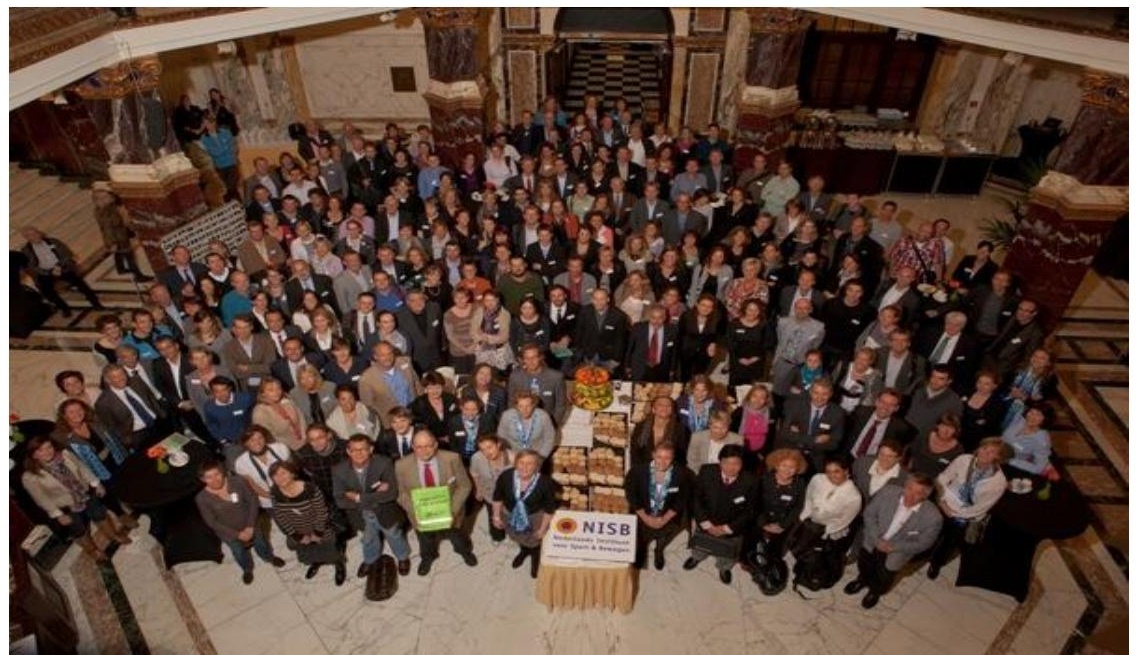

